\title{
The use of forest restoration techniques in the restoration of coral reefs
}

\begin{abstract}
Human-induced (anthropogenic) impacts to coral reefs include dredging, fishing, chemical pollution, oil spills, ship groundings, tourist damage, and run-off of sediment, fertilizer, and pesticides. Wider scale impacts, such as global climate change, have triggered mass coral bleaching events and subsequent mortality, and ocean acidification has led to decreases in the structural integrity of reefs. As human populations continue to increase in coastal areas, the demand for reef-associated resources (reef fish, mollusks, algae and crustaceans) will rise. Because coral reefs are experiencing dramatic loss of coral cover and associated species, there is a critical need for restoration strategies to be applied to coral reef ecosystems. "Due to the biological, structural and functional analogies between trees and corals, it is natural to propose that silviculture concepts can assist in reorganizing the theoretical and practical priorities for coral reef restoration so that a solid restoration framework can be developed for the marine realm. The strategy of coral mariculture and gardening may potentially prove to be a sustainable practice for reef restoration, comparable to forest silviculture". Trees and stony corals have one thing in common; they are both significant structural components and the basic building blocks of their respective ecosystems - forests and coral reefs. ${ }^{1}$ Through the analysis of forest and coral reef literature, connections between forest and coral reef ecosystems and their restoration efforts will be reviewed and compared. Since trees and corals share biological, structural and functional similarities, successful forest restoration techniques are applicable to coral reef restoration. In this paper I will summarize these similarities and justify the use of forest restoration techniques on coral reefs through literature review.
\end{abstract}

Keywords: Coral, Biodiversity, Ecosystem, Mariculture, Restoration, Silviculture, Tree, Transplantation
Volume 2 Issue I - 2015

Tiffany Babcock

Nova Southeastern University, USA

Correspondence: Tiffany Babcock, Nova Southeastern
University, USA, Tel +8566858I79, Email tiffanybabcock@gmail.com

Received: December 02, 2014 | Published: December 31, 2015

\section{Introduction}

Coral gardening is a tool useful in restoring coral reefs and is comparable to silviculture through source material, location, type, choice of species and outcome (Table 1). For both trees and corals, resource requirements are similar and include inorganic substances, light, and space. ${ }^{2}$ Key criteria for both forest and coral reef restoration include promotion of asexual and sexual reproduction, allowing restored systems to maintain themselves. Asexual culture of corals has great potential in reef restoration in a similar way to how silviculture in land-based nurseries supports forest reforestation projects. ${ }^{3}$ For forests, ramets, seeds, and seedlings are used; for reefs, ramets, nubbins, planulae, larvae, and spat are forms of source material. Locations for forest restoration projects are often located in degraded forest areas or on plantations; for reefs, coral nurseries are constructed on or adjacent to degraded reefs or established in landbased aquaculture facilities for later transplantation. Tree species are collected from mono-culture or mixed species plantations as well as natural forests and coral species are collected from marine culture of local key coral species. ${ }^{1}$

One reason for the need of both forest and coral reef restoration is anthropogenic impact. Humans have long influenced ecosystems on various temporal and spatial scales. In the terrestrial realm, habitat conversion from forest land to agricultural land and finally to degraded land has continued to be the biggest problem in our current biodiversity crisis. Reports indicate that tropical and temperate forests are destroyed at a rate of between $1 \%$ and $4 \%$ annually. In addition, habitat conversion is concentrated on ecosystems that only retain agricultural productivity of between 3 and 5 years; this land is then abandoned upon the invasion of weeds or when erosion carries away fertile top soil. The result of habitat conversion is longterm loss of biological diversity; this is because as these degraded areas accumulate, natural colonization and succession takes place at a slower rate producing reduced and weaker fauna and flora. ${ }^{4}$ Widespread clearing may lead to local extermination of important, formerly common pioneer species and mid- and late-succession plant and animal species. This translates to a much slower rate of recovery. According to models of habitat loss, these rates of recovery leads to "extinction debt," representing a pool of organisms that will ultimately become extinct if habitat restoration is not carried out. ${ }^{5}$

Similarly, coral reef systems are affected by uncontrolled collecting, sport fishing, and accidental damage (by waders, swimmers, and boat anchors); this causes reductions of important reef inhabitants and threatens biodiversity. Also, local and/or tourist demand for seafood can result in over-exploitation of locally caught fish and invertebrates. The building and operation of tourist facilities can also be damaging, particularly if untreated sewage and other wastes contaminate adjacent waters. ${ }^{6}$ Sediment runoff from construction and ground cover removal (a possible confluence of the two ecosystems under comparison in this capstone) often causes high coral mortality, rapid growth of fleshy algal species, and large parcels of reduced salinity/quality of seawater. In the case of decreased water quality, corals may have complications receiving chemical cues which allow for synchronous spawning.? There is a need for careful control, monitoring, and design of coastal development projects to avoid problems such as increased beach erosion e.g. not placing them directly on beaches and exacerbating erosion. ${ }^{6}$ 
Table I Comparison of key criteria for forest and coral reef restoration'

\begin{tabular}{|c|c|c|}
\hline & Trees & Corals \\
\hline \multirow{3}{*}{$\begin{array}{l}\text { Source material } \\
\text { for farming }\end{array}$} & Asexual: ramets & Asexual: ramets, nubbins \\
\hline & Sexual: seeds, seedlings & Sexual: Planula larvae, spat \\
\hline & Directly on degraded forest land & In situ nurseries \\
\hline \multirow[t]{2}{*}{ Location } & -or- & -or - \\
\hline & Selected sites for plantations & Ex situ aquaculture \\
\hline Type & Young trees to cover land in denuded sites & $\begin{array}{l}\text { New coral colonies to replace dead corals or } \\
\text { create new nuclei in denuded zones }\end{array}$ \\
\hline Impact on & Root system: stabilizing soil. Enhanced litter production; increased soil & Enhanced lithification processes. \\
\hline Substrate & organic matter, moderating soil $\mathrm{pH}$, and improving nutrient status & Enhanced reef rock formation. \\
\hline \multicolumn{3}{|c|}{ Similarities between both ecosystems } \\
\hline & $\begin{array}{l}\text { No detrimental impact on environment } \\
\text { Greenhouse needed for sustainable number of recruits }\end{array}$ & \\
\hline Rationale & $\begin{array}{l}\text { Nursery survivorship is higher than in under natural conditions } \\
\text { Stock material is available upon immediate request } \\
\text { Direct controlling of species abundance }\end{array}$ & \\
\hline $\begin{array}{l}\text { Species of } \\
\text { Choice }\end{array}$ & High performance in restoration situations & \\
\hline \multirow[t]{2}{*}{$\begin{array}{l}\text { Ecological } \\
\text { properties }\end{array}$} & Facilitating subsequent recruitments, preventing takeover by weedy species & \\
\hline & Restoring productivity, stability and biodiversity & \\
\hline $\begin{array}{l}\text { Overall } \\
\text { ecological impact }\end{array}$ & $\begin{array}{l}\text { Restoring associated fauna and flora } \\
\text { Increasing spatial resilience of ecosystems } \\
\text { Speeding the recovery of degraded habitats }\end{array}$ & \\
\hline
\end{tabular}

Global warming and ocean acidification occur over long time periods and large distances. ${ }^{3}$ Global warming both directly and indirectly impacts the growth and productivity of forests and coral reefs; directly because of the changes in carbon dioxide in the atmosphere and indirectly as a result of complex interactions in forest ecosystems. ${ }^{8}$ Global warming also promotes the northward migration of certain trees, leading to migration of associated species and ecological tension, which in turn creates tree fall gaps offering a pathway for future migration. ${ }^{9}$ For example, the lodgepole pine has been extending its northern limits. ${ }^{10,11}$

Recently, it was discovered that tropical trees respond to climate change via distributional migrations over short (sub-decadal) timescales. For example, several tree genera in the Peruvian Andes have increased their elevation limit. ${ }^{12}$ Furthermore, it is predicted that shift changes in forest composition will take place (Figure 1); an example being in the Northeast; current dominant maple-beech-birch forest will be displaced with the northern migration of oak-pine and oakhickory forest. ${ }^{13}$

In a similar fashion, coral species such as Acropora cervicornis and $A$. palmate have expanded their geographic ranges northward along the east coast of the Florida Peninsula and into the northern Gulf of Mexico as sea surface temperatures warm. Thickets of $A$. cervicornis were discovered off Fort Lauderdale in Broward County, where they had not been observed during the 1970s and 1980s (Figure 2). Recently, A. palmata, have been observed as far north as Pompano Beach in northern Broward County and in 2002 observed on the reefs of the Flower Garden Banks in the northern Gulf of Mexico. These corals are migrating northward along the east coast of Florida due to the pole-ward transport of warm water, via the Florida Current and northward into the Gulf of Mexico via the warm GulfLoop Current. These consequences of climate change at the species-level hint at community-level changes in composition and distribution of coral reef ecosystems. ${ }^{14}$ This northward extension of habitable environment and concomitant range extensions are important factors to consider when restoration is attempted. It may be possible to enlarge historical habitats for both forests and reefs, making "restoration" a mechanism of habitat change. This modification of existing ecosystems should be carefully considered before implementation.

In its purest form, ecological restoration is an effort to return a system to its undisturbed natural state, but more realistically, to restore a damaged system to a less disturbed state (an ecological state within acceptable limits). ${ }^{15}$ Maintenance of key ecosystem functions through restoration of biodiversity, and in particular keystone species (species which perform a vital function for the ecosystem) is an important step in the restoration of any ecosystem. ${ }^{1}$

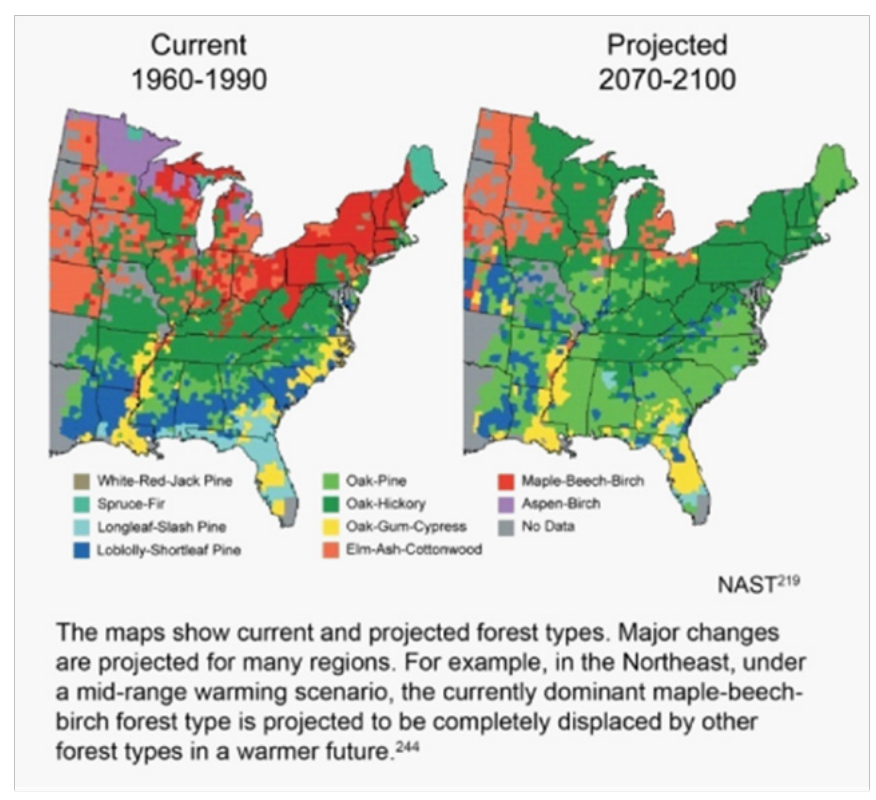

Figure I Current and project forest types. ${ }^{13}$ 


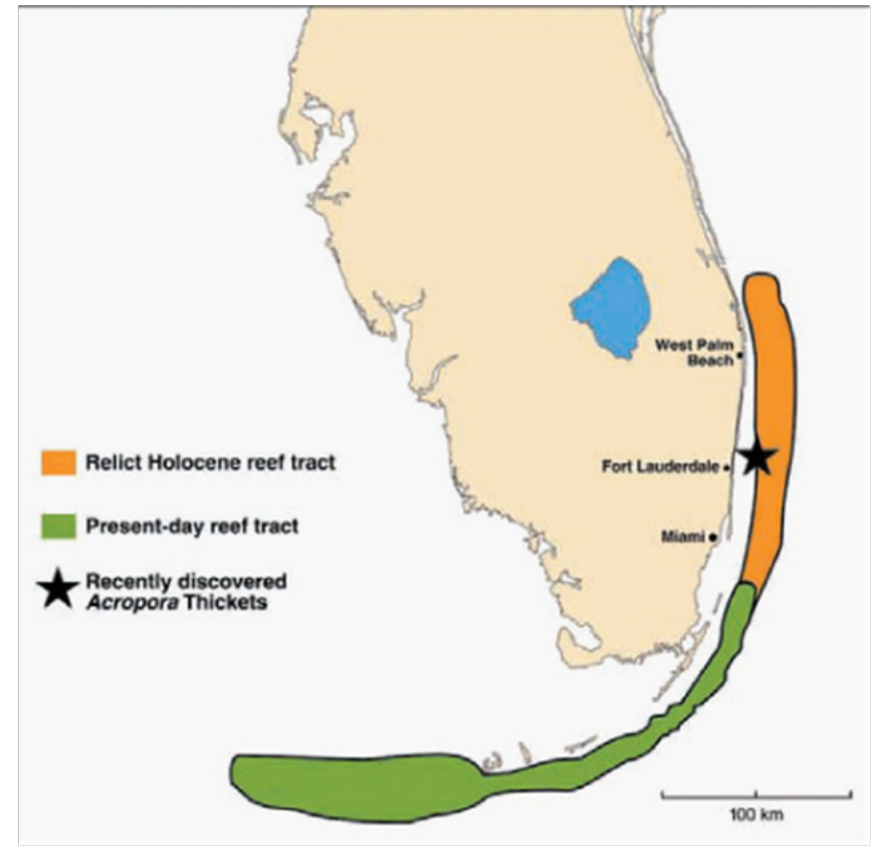

Figure $\mathbf{2}$ Location of recently discovered acroporid coral thickets. ${ }^{14}$

This paper describes the various aspects of ecosystem restoration with specific reference to both forest restoration (silviculture) and coral reef restoration (coral gardening). I will empirically examine current forest restoration techniques, and how these methods can be used in coral reef restoration. The first section, Ecosystem Restoration, discusses the importance of restoration to both the environment and its inhabitants, and the reasons for ecosystem restoration in terms of increasing biodiversity and maintenance of ecosystem key functions.

Ecosystem restoration is then divided into three sub-sections; forest restoration, a review of past coral reef restoration methods, and then forest and reef restoration strategies are compared and contrasted in terms of the structural elements (corals and trees), and artificial population supplementation (silviculture and mariculture, coral gardening, and source material). Finally, I will explain why coral gardening is preferred over past methods. Based on the number of problems related with direct coral transplantation, the paper proposes solutions in respect to reef conservation and management.

\section{Discussion}

\section{Comparisons between Forest and Coral Reef Restoration Efforts}

"Coral reefs are often called "the rain forests of the oceans" because they are among the richest marine ecosystems in species, productivity, biomass, structural complexity, and beauty. Like rain forests, reefs provide evolutionary lessons from intricate interactions between organisms. Both rely on structural frameworks built by a single group of living organisms: trees in forests and corals in reefs. Like rain forests, coral reefs thrive in nutrient-poor habitats by containing many species whose complex food chains recycle essential nutrients with great efficiency, making reefs especially sensitive to any process that disrupts recycling". ${ }^{16}$

\section{Trees and Corals}

In recent decades, both, forest and coral ecosystems have undergone rapid degradations in structure and biodiversity due to rise in atmospheric carbon dioxide, temperature increases, ocean acidification, and population level shifts. ${ }^{8}$ The changes have affected both trees and coral reefs as the ecosystems show reductions in four parameters; capacity for ecological resilience, capacity to absorb disturbances, their ability to reorganize, and to respond to changes. The main focus of this capstone is to determine if it is possible to make use of the lessons learned from silviculture to help restore coral reefs. ${ }^{1}$ Since these ecosystems face similar challenges, similar restoration techniques may be practical.

The similarities of biological structure and function between trees and corals make it appealing to apply silviculture concepts to coral reef restoration. ${ }^{1}$ Trees and corals can be propagated by sexual and asexual means. Fragments (branches), seeds and seedlings are used for restoring trees, compared to ramets, nubbins, planulae and spat used for restoring corals. Trees and corals have a direct effect on 3-dimensional structure in their respective ecosystems, and affect the substrata. Trees make soil stable, promote the formation of litter, raise soil organic matter, and corals promote lithification process, and boost the formation of reef rock. In addition, both the trees and corals enhance the spatial resilience of the ecosystem. ${ }^{17}$

Being the basic habitat builders, trees and corals are not only similar in their influences upon the ecosystems' structural features, but are also similar in architectural rules of their growth characteristics and in pattern formation. ${ }^{18}$ Both the trees and corals provide the basic ecosystem structure, protecting associated organisms, and other ecosystems in their lee, from mechanical disturbance associated with storm energy. ${ }^{19}$ Trees directly buffer the understory from high winds and rainfall and reduce topsoil loss, while corals act as wave-resistant structures buffering inshore habitats from strong water motion. ${ }^{20}$

\section{Silviculture and Mariculture}

Silviculture, simply defined as the agriculture of trees, relates to how trees are grown, how to maximize their growth, and how to manipulate different tree species in order to meet ecological and societal goals. Silvics is an important aspect of silviculture; it refers to the understanding of how trees grow, how they reproduce, and their response to environmental changes. Silviculture has found application in the restoration of terrestrial habitats especially in instances where natural recovery of forests has failed. Silviculture arose because of the failure of forest systems to regenerate naturally; this, in turn, led to the development of numerous restoration measures that have proved effective in the long-run. These recent restoration developments have been successful in drawing back the trend of decline and in generating novel habitats for diversity. ${ }^{21}$ According to Anderson and Palik, ${ }^{22}$ silviculture can be used to combat impacts associated with climate change via increasing the amount of tree plantations across the globe through the creation of appropriate seedbeds and minimization of vegetation competition therefore leading to an increase in global plant biomass. This increased forest coverage reduces the excess carbon dioxide in the atmosphere thus, reducing one atmospheric driver of global warming and erosion of coral reefs.

Considering the structural and functional similarities between forest trees and reef-building corals, concepts of silviculture could play a meaningful role in coral reef restoration. ${ }^{17}$ Terrestrial habitat restoration typically occurs in three steps: the 1) re-introduction of vegetation where there is collection of different tree seeds, 2) rearing the seeds in nurseries installed in sheltered zones and then 3 ) transplanting the seedlings into degraded forest sites. ${ }^{23}$ Because forest restoration has been successful, these methods may be applicable to the coral gardening concept that consists of three main steps: 1) 
the collection of coral recruits (spats, nubbins, coral fragments, and small coral colonies); 2) rearing the corals in large in situ and/or ex situ nurseries installed in sheltered zones; and 3) transplantation of the size-adequate coral colonies onto degraded reef sites. ${ }^{24,2}$

In highly disturbed areas, the first step in forest restoration is repairing the biological and mechanical properties of the substrate (soil) in order to support species re-introduction. In forests, part of a successful long-term environmental intervention may entail the introduction of nitrogen fixing plant species such as herbaceous legumes which include Trifolium and Lespedeza..$^{21}$ Nitrogen fixation is crucial to all re-growth projects as nitrogen is essential to plant life (as well as marine life). ${ }^{25}$ After intervention has assisted in restoring soil characteristics, it becomes easier to restore a full suite of plant species, establishing the necessary vegetation for successful successional sequences. The commonly used method entails choosing species significant in the restoration of ecosystem function, species that will form the main structural component of the final ecosystem while allowing space for numerous plant and animal species that will contribute to the biodiversity of the climax ecosystem. Strategic transplantation of key species allows other important biotic component groups to colonize on their own. ${ }^{21}$.

However, the substrate needs of corals are different than for trees. Corals do not obtain nutrients from sediment/soil; corals receive nutrients from the water column. ${ }^{26}$ Corals need a bare substratum to settle on and attach to, free from competitive algae or other invertebrates. This is typically either a carbonate substrate from a previously degraded reef or artificial substrata (e.g. reef balls, triangular prisms, concrete, or ship material). Following substrate renewal is community restoration; in forests this involves the choice and transplantation of 1) species important for restoring ecosystem function; 2) species that will become the main component of the final ecosystem; and 3) plant and animal species that will contribute to the biodiversity of the ecosystem and be able to maintain populations on their own. Community restoration follows substructure repair for coral reefs as well. Substrate repair through the use of hydraulic cement to re-attach broken structures, slabs of concrete to replace pulverized material, or replacement 3-dimensional structures such as reef balls, allow attachment locations for initial coral transplants and subsequent natural recruits. ${ }^{21}$

Coral transplantation is used effectively in the restoration for coral reefs; it is a means of rehabilitating coral reefs, particularly on substrata that are not favorable to post-recruitment survival or larval recruitment, by bypassing the vital early stages of coral recruitment. However, efforts to restore degraded coral reefs necessitate a fundamental understanding of the natural recovery process and the conditions that will improve success. ${ }^{27}$ Archaux and Bakkaus ${ }^{28}$ posited that to overcome problems caused by the traditional transplantation techniques one should apply a gardening concept called silviculture, which comprises of two phases: first, large numbers of corals are cultured in underwater nurseries and second, the cultured colonies are transplanted into damaged reefs regions. One important technique used in coral reef restoration is mariculture; the term encompasses the growth of marine organisms in controlled environments that can be used in restoration and maintenance. This concept, if embraced in various regions of the world, may shape the theoretical and practical platform for reef rehabilitation activities. Concerning transplantation, when compared to the damaging practice of harvesting from established coral colonies, the use of coral nurseries removes the necessity to reduce ecologically valuable coral material from natural environments. If coral nurseries are located near the target site, this allows time for the coral to adapt to local conditions, improving chances of survival and growth following transplantation. ${ }^{29}$

According to Epstein, ${ }^{17}$ coral mariculture involves application of in situ nurseries as well as ex situ aquaculture facilities, which forms a practical and conceptual platform for activities involved in reef restoration. The approach of coral mariculture by use of the gardening concept seems to be the first such sustainable method for reef rehabilitation. It is important to note that the concept of coral gardening is a superior strategy when compared to the more contemporary and extensively used "coral transplantation" method which is made imperfect by the necessity to gather colonies from surviving populations. ${ }^{29}$

Epstein ${ }^{17}$ further asserts that the development of nurseries that include local species eliminates the need for coral material extraction for transplantation. The protection of nursery phases offers the relocated material an adjustment period which ensures better survival rates and development to a suitable size for transplantation. The transplants in the nursery are then sent back into the natural reef habitat so as to mitigate genes and species destruction in degraded areas. ${ }^{30}$ Epstein ${ }^{17}$ indicates that nurseries for the transplants are very effective in enhancing the survivorship and development of coral material; moreover, such nurseries tend to reduce the challenge of regulating fouling and corallivorous life forms.

In silviculture, the transplantation of nursery established "seedlings" has beneficial impacts in that it prevents the loss of genets and species in denuded sites thus protecting genetic diversity. Similarly, coral nurseries serve as a diverse pool for local species which provides reef-managers with a ready supply of corals, thus helping to ensure sustainability. Growing of corals in underwater nurseries has an additional benefit as it helps in structuring 3-D profiles within the growing colonies. ${ }^{17}$ Essentially, the taxa used for restoration are not randomly chosen, but they have to be able to contribute to reef structural integrity. This often involves the use of fast-growing and structurally significant branching corals.

Forest restoration can often be classified into three different scientific approaches: genetics, site preparation, and, like mariculture, nursery preparation. When referring to "site preparation", this includes both the physical cultivation and preparation of the soil and the use of chemicals such as fertilizers, insecticides and other treatments that are used during the establishment of plantations. Nursery researchers are biased towards out planting nursery treatments whereas geneticists have an inclination towards out planting progeny trials. Likewise, silviculturalists are biased towards evaluation of site preparation measures. It is as a result of these three different routes and the different approaches that studies entailing all three major classifications are rare, even those that make use of two categories are uncommon. In fact, trials combining nursery treatments with site preparation are not common. $^{31}$

Despite the fact that forest restoration has been a key component of conservation, protection, and maintenance of biodiversity for over a century, it has faced various challenges in the unification of concepts. For instance, a great disparity in modes of forest preservation exists in different regions in Europe due to lack of economic incentives, limited investment, lack of political will and public awareness, ineffective procedures and inadequate institutional framework for ensuring forest integration. In addition, the ways in which forests have been used in the past, their closeness to major towns and in the definition of what makes a forest influences the preservation of the forests. This way, even in silviculture, a single, uniform and a generally accepted model 
and goal for restoration is lacking. Various methods including spatial heterogeneity, promotion of biodiversity in plantations, silviculture systems and structural analysis are some of the common restoration practices used in denuded forests. ${ }^{32}$ Additionally, an exciting model termed the "close-to-nature silviculture" concept was unveiled towards the end of the 19th century. The concept was found to be in line with the "returning to nature" paradigm that was common during the period..$^{33}$ This concept and other silvicultural ideas and principles are significant in the establishment of an active reef restoration.

Jackson. ${ }^{34}$ stated that if the secondary forest trees remain undisturbed by recurring disturbances such as wild fires and tree felling, secondary forest trees might be slowly outcompeted by the primary forest trees and this can eventually lead to the development of a pristine forest. Aligned with this perspective, lack of pristine baseline for both the forest and reef restoration plagues the present understanding of global ecosystem and restricts our ability to do much about it. For instance, Jackson $^{34}$ indicated that the late Pleistocene fossil record illustrates that coral communities display remarkable permanence in species composition and relative richness of dominant species. Comparison between the few remaining pristine reefs with exploited reefs yielded an immense difference in fish diversity, coral generic richness, and coral cover ${ }^{35}$ In order to maintain these valuable ecological resources, there is a need for active restoration for coral reefs.

\section{Conclusion}

Humans have had a wide range of impacts on ecosystems via accidents, industrial pollutions, and habitat destruction. These human impacts occur over large areas of the Earth decreasing available habitat for species and ultimately reducing biodiversity. As human populations increase on coastal areas, the demand for reef resource increases. Because coral reefs are decreasing quickly, there is a critical need for restoration strategies to be applied to coral reef ecosystems. Direct human intervention will continue to be needed and will in the future be an essential measure. Coral gardening seems to offer some hope for the future because it can be applied to various reef locations.

The management of the ecosystem, both terrestrial and marine habitats, is linked connected to socio-political, economic and ecological aspects. Therefore, properly planned restoration practices will play an important role as it may reduce recovery lag. The practice should therefore be made a standard component of conservation practices. ${ }^{36}$

In conclusion, the biological, structural and functional analogies between trees and corals, allow the application of silviculture concepts to assist in coral reef restoration. This is through the use of coral nurseries to develop more corals for transplantation onto reefs as the restoration of coral reefs is important due to the role it plays in development. A primary goal of restoration ecology focuses on species diversity and the maintenance of key ecosystem functions. Consequently, silviculture practices are analogous to coral gardening through source material, location, type, choice of species and immediate target. For both trees and corals, resource requirements are similar and include inorganic substances, light, and space. Finally, species with high performance in restoration situations are the best species in both forest and coral reef ecosystems. Thus, the ideas that have been successful in forest restoration can be effectively used in coral reef restoration. From this point of view, it is worth stating that forest restoration techniques can be applied in the restoration of coral reefs.

Through literature review of forest ecosystems, I have learned that the main concern in ecosystem management is whether human intervention should occur, and if so, should it be in the form of reclamation or restoration. For instance, a forested area can be completely destroyed via mining activities in which the complete ecosystem has been lost and restoration is impossible, therefore, it may be more feasible to replace the disturbed site with a new system via reclamation. ${ }^{37}$ In order to determine which actions to take, certain steps should be followed (Table 2).

Table 2 Best Management Practices

\begin{tabular}{|c|c|c|}
\hline $\begin{array}{l}\text { S. } \\
\text { No }\end{array}$ & Best Management Practices & Example \\
\hline I & Define the problem & $\begin{array}{l}\text { Coral reef population } \\
\text { destroyed }\end{array}$ \\
\hline 2 & Define the cause & Ship grounding \\
\hline 3 & Define the extent of cause & Non-reoccurring \\
\hline 4 & Define the impacts & $\begin{array}{l}\text { Reduced porosity, structure, } \\
\text { species richness, biodiversity, } \\
\text { productivity, function }\end{array}$ \\
\hline 5 & Define the severity of impacts & $\begin{array}{l}\text { Completely lost. Nothing } \\
\text { remaining. No life. }\end{array}$ \\
\hline 6 & $\begin{array}{l}\text { Decide if reclamation or } \\
\text { restoration should be carried } \\
\text { out }\end{array}$ & Reclamation \\
\hline
\end{tabular}

Best Management Practices

When evaluating an ecosystem, the first step is to define what the problem is. Then one would determine what is causing the problem and whether this cause is re-occurring or not. The impacts and their severity on the disturbed ecosystem as well as surrounding ecosystems should then be evaluated. Once steps 1-5 have been followed, an educated decision on whether to perform reclamation or restoration will be made (Table 2). As shown in the example, a ship grounding completely destroyed a reef requires reclamation actions rather than recovery because the area was left nearly barren.

\section{Future Concerns}

A significant concern with respect to coral reef restoration is the prospects of a sharp downturn in coral cover and species diversity in this important ecosystem. Since the broad diversity of tropical marine life is based upon the success and proliferation of coral species, it stands to reason that coral destruction would lead to small cascading effects in many areas..$^{20}$ Past restoration actions have been regarded as responses to pervasive efforts of human actions and not to natural disaster; it is not pertinent that degradation of coral reefs by natural and manmade disasters to be treated equally. Application of restoration on a larger scale should be further researched..$^{38}$

Not only should physical restoration be taken but there appears to be a need for genetic restoration because decreased gene flow may drastically alter a species genetic architecture and disrupt local adaptation. Results from studies on gene pools in restored terrestrial habitats should be further looked into for applicability to coral reef restoration. Restoration should range from recreation of the original ecosystem to the reconstruction of entirely alternative, new ecosystems. ${ }^{38}$ "With more scientific background and concepts integrated with other biological disciplines (genetics, molecular biology, theoretical ecology, etc.), coral reef restoration measures will achieve far greater success than our present meager knowledge can". ${ }^{38}$ "The restoration of coral reefs, therefore, should become a standard part of conservation practices, and when applied, already tested and approved forest restoration principles may provide important insight into the understanding of the reef ecosystem recovery". 


\section{Acknowledgments}

None.

\section{Conflicts of interest}

None.

\section{References}

1. Epstein N, Bak R, Rinkevich B. Applying forest restoration principles to coral reef rehabilitation. Aquatic Conservation: Marine and Freshwater Ecosystems. 2003;13(5):387-395.

2. Connell JH. Diversity in tropical rain forests and coral reefs. Science. 1978;199:1302-1310.

3. Edwards A, Gomez E. Reef restoration concepts and guidelines: Making sensible management choices in the face of uncertainty. Coral Reef Targeted, Australia. 2007;pp.38.

4. Reid W, Miller K. Keeping Options Alive: The Scientific Basis for Conserving Biodiversity. World Resources Institute, Washington, USA. 1989.

5. Reid W. How many species will there be? In: TC Whitmore and JA Sayer Tropical (Eds.), Deforestation and Species Extinction, Chapman \& Hall, London. 1992;pp.55-73.

6. Sudara S, Nateekarnchanalap S. Impact of Tourism Development on The Reef in Thailand. Coral Reef Symposium. 1988;2:273-278

7. Richmond RH. Coral reefs: present problems and future concerns resulting from anthropogenic disturbance. American Zoologist. 1993;33(6):524-536.

8. Grogan J, Schulze M. The Impact of Annual and Seasonal Rainfall Patterns on Growth and Phenology of Emergent Tree Species in Southeastern Amazonia, Brazil. Biotropica. 2012;44(3):331-340.

9. Leithead MD, Anand M, Silva LC. Northward migrating trees establish in treefall gaps at the northern limit of the temperate-boreal ecotone, Ontario, Canada. Oecologia. 2010;164(4):1095-1106.

10. Neilson RP, Pitelka LF, Solomon AM, et al. Forecasting regional to global plant migration in response to climate change. Bioscience. 2005;55(9):749-759.

11. Johnstone JF, Chapin FS. Non-equilibrium succession dynamics indicate continued northern migration of lodgepole pine. Global Change Biology. 2003;9(10):1401-1409.

12. Feeley KJ, Silman MR, Bush MB, et al. Upslope migration of Andean trees. Journal of Biogeography. 2011;38(4):783-791.

13. EPA. Forest Impacts \& Adaptation. United State Environmental Protection Agency. 2013.

14. Precht WF, Aronson RB. Climate flickers and range shifts of reef corals. Frontiers in Ecology and the Environment. 2004;2(6):307-314.

15. Clewell AF, Aronson J. Motivations for the Restoration of Ecosystems. Conservation Biology. 2006;20(2):420-428.

16. Goreau T. Coral reefs: Rain forests of the ocean. In: RA Eblen \& WR Eblen (Eds.), The Encyclopedia of the Environment, Houghton Mifflin, Boston. 1994

17. Epstein N, Rinkevich B. From isolated ramets to coral colonies: the significance of colony pattern formation in reef restoration practices. Basic and Applied Ecology. 2001;2(3):219-222.
18. Dauget J. Application of tree architecture models to reef-coral growth forms. Marine Biology. 1991;111(1):157-165.

19. Epstein N, Bak R, Rinkevich B. Strategies for gardening denuded coral reef areas: The applicability of using different types of coral material for reef restoration. Restoration Ecology. 2001;9(4):432-442.

20. Green EP, Bruckner AW. The significance of coral disease epizootiology for coral reef conservation. Biological Conservation. 2000;96(3):347361 .

21. Dobson AP, Bradshaw AD, Baker AJM. Hopes for the Future: Restoration Ecology and Conservation Biology. Science. 1997;227:515-521.

22. Anderson P, Palik B. Regional examples of silvicultural adaptation strategies. Western Great Lakes Mixed-Pine Ecosystem. 2011;98(6):225289.

23. Adamus P. Protection, restoration and management of terrestrial habitats and species of the Willamette sub-basin, Terrestrial technical. 2011.

24. Rinkevich B. Management of coral reefs: We have gone wrong when neglecting active reef restoration. Mar Pollut Bull. 2008;56(11):18211824.

25. French P. Coastland \& Estuarine Management. Routledge Environmental Management Series. 1997.

26. Finelli CM, Helmuth BS, Pentcheff ND, et al. Water flow influences oxygen transport and photosynthetic efficiency in corals. Coral Reefs. 2006;25(1):47-57.

27. Lindahl U. Low-tech restoration of degraded coral reefs through transplantation of staghorncorals. Ambio. 1998;27(8):645-650.

28. Archaux F, Bakkaus N. Relative impact of stand structure, tree composition and climate on mountain bird communities. Forest Ecology and Management. 2007;247(1-3):72-79.

29. Sinsch U. Postmetamorphic dispersal and recruitment of first breeders in Bufo calmamita metapopulation. Oecologia. 1997;112:42-47.

30. Horoszowski-Fridman YB, Izhaki I, Rinkevich B. Engineering of coral reef larval supply through transplantation of nursery-farmed gravid colonies. Journal of Experimental Marine Biology and Ecology. 2011;399(2):162-166.

31. South D, Rose RW, McNabb L. Nursery and site preparation interaction research in the United States. New Forests. 2001;22(1):43-58.

32. Parviainen J, Frank G. Protected forests in Europe approachesharmonizing the definitions for international comparisons and forest policy making. J Environ Manag. 2003;67(1):27-36.

33. Schutz J. Close-to-nature silviculture: is this concept compatible with species diversity? Forestry. 1999;72(4):359-366.

34. Jackson JBC, Alexander KE, Sala E. Shifting baselines, the past and the future of ocean fisheries, Island Press Chapter. 2011;11:193-203.

35. Knowlton N, Jackson JB. Shifting baselines, local impacts, and global change on coral reefs. PLoS Biol. 2008;6(2):e54

36. Tucker B, Anand M. The Application of Markov Models in Recovery and Restoration. International Journal of Ecology and Environmental Sciences. 2004;30:131-140.

37. Harrington C. Forests planted for ecosystem restoration or conservation. New Forests. 1999;17(1-3):175-190.

38. Rinkevich B. Conservation of coral reefs through active restoration measures: Recent approaches and last decade progress. Environmental Science and Technology. 2005;39(12):4333-4342. 